\title{
Desafios e perspectivas do programa de aquisição de alimentos no município de Tupã -SP
}

\author{
Challenges and perspectives of Food Acquisition Program in the municipality of \\ Tupã, São Paulo, Brazil
}

\author{
Mara Elena Bereta de Godoi Pereira ${ }^{1}$, Ana Elisa Bressan Smith Lourenzani ${ }^{2}$ \\ ${ }^{1}$ Universidade Estadual Paulista Júlio de Mesquita Filho, SP, Brasil
}

\begin{abstract}
Resumo
O Programa de Aquisição de Alimentos (PAA) constitui-se como uma das ações do Programa Fome Zero que visa atender as populações em situação de insegurança alimentar e nutricional. Trata-se de uma política pública que busca fortalecer a agricultura familiar e atender àqueles que não têm acesso aos alimentos em quantidade, qualidade e regularidade necessárias. O presente trabalho teve como objetivo verificar os desafios e as perspectivas do PAA no município de Tupã - SP. Para tal foi realizada uma pesquisa descritiva, empírica e teórica com produtores familiares participantes do PAA. Os resultados indicaram a importância do Programa para escoamento do excedente da produção e o seu impacto no aumento da renda percebida pelo agricultor familiar. O PAA tem sido instrumento de fortalecimento da agricultura familiar no município, porém, a falta de ações coletivas concretas e operacionalização correta do Programa são gargalos a serem superados para que o seu objetivo seja alcançado.
\end{abstract}

Palavras-chave: agricultura familiar. comercialização. políticas públicas. Programa de Aquisição de Alimentos.

\begin{abstract}
The Programa de Aquisição de Alimentos (PAA) is part of Fome Zero Program that aims to attend populations in situation of food and nutritional insecurity. It is a public policy that aims at strengthening family based farming and helps those who have no access to food in necessary quantity, quality and regularity. This research aimed at verifying the challenges and perspectives of PAA in the municipality of Tupã, SP, Brazil. A descriptive, empirical and theoretical research was performed in order to reach the objectives. The results indicate the importance of the Program for selling the remaining production and its impact on income. The PAA has been an instrument of strengthening family based agriculture in the municipality, however, the lack of concrete collective actions and correct operationalization of the Program are bottlenecks to be overcome for a better performance.
\end{abstract}

Keywords: family based farmers. commercialization. public policy. The Food Acquisition Program 


\section{Introdução}

Segundo o último Censo Agropecuário (IBGE, 2006), o Brasil possui 4.367.902 estabelecimentos da agricultura familiar, o que corresponde a $84,4 \%$ do total. Contudo, estes estabelecimentos ocupam uma área de 80,25 milhões de hectares, que corresponde a $24,3 \%$ do total de área ocupada por estabelecimentos agropecuários. Já aqueles classificados como não familiares representam $15,6 \%$ do total de estabelecimentos e ocupam $75,7 \%$ do total de área ocupada. Isto demonstra o quão desigual e concentrada é a distribuição de terras no país.

A agricultura familiar ${ }^{1}$ tem papel relevante na economia e sociedade. Considerando a produção de alimentos para o mercado interno verifica-se que a agricultura familiar produz: $87 \%$ da produção da mandioca, $70 \%$ do feijão, $46 \%$ do milho, $38 \%$ do café, $34 \%$ do arroz, $58 \%$ do leite (este percentual considera juntos o leite de vaca e o de cabra), $59 \%$ do plantel de suínos, $50 \%$ de aves e $30 \%$ dos bovinos (IBGE, 2006). Ela é a fornecedora de produtos de primeira necessidade que garantem a segurança alimentar e nutricional da população (BRASIL, 2011). Também é geradora de insumos para outros mercados, abastecendo principalmente o mercado interno seja no comércio de produtos in natura ou como matéria-prima para a indústria de produtos processados.

Fatores climáticos, sazonalidade, preços praticados pelo mercado, dificuldade de obtenção de crédito para financiamento da produção e/ou investimento em infraestrutura e equipamentos visando à melhoria da qualidade da produção, escoamento da produção, dificuldade de acesso ao mercado são algumas das barreiras encontradas pelos agricultores familiares.

Para Souza Filho e Batalha (2005) um importante gargalo para o crescimento da agricultura familiar é a comercialização. O conhecimento na agricultura familiar é transmitido de geração a geração e a comercialização é praticada de forma tradicional. Por produzir em escalas menores e muitas vezes não contar com espaço físico adequado para armazenar seus produtos, o produtor familiar tem dificuldade em receber na venda de seu produto um valor justo que corresponda ao valor investido na produção. Há ainda que se considerar a perecibilidade dos produtos não processados, o que pode dificultar o processo de comercialização.

Para Buainain e Pires (2003) "[...] o funcionamento e eficácia do mercado são afetados pela estrutura de poder e pela desigualdade social, e que as falhas de mercado tendem a ser mais graves em situações de forte desigualdade". Segundo Carvalho (2001, p. 122), "Considera-se falha do mercado o conjunto de condições sob as quais uma economia de mercado

1 Para atender ao objetivo proposto nesse estudo utilizou-se como parâmetro para caracterização da agricultura familiar, a Lei 11.326 de 24 de julho de 2006, que estabelece as diretrizes para a formulação da Política Nacional da Agricultura Familiar e Empreendimentos Familiares Rurais. Nela, considera-se agricultor familiar e empreendedor familiar rural aqueles que não detenham área maior do que 4 (quatro) módulos fiscais; utilizem predominantemente mão-de-obra da própria família nas atividades econômicas; tenham percentual mínimo da renda familiar originada de atividades econômicas do seu estabelecimento ou empreendimento, na forma definida pelo Poder Executivo; dirijam seu estabelecimento ou empreendimento com sua família. (BRASIL, 2012C). é incapaz de distribuir recursos de maneira eficiente". Podemos citar como falhas de mercado a competição imperfeita, informação imperfeita, mercados incompletos, externalidades e bens públicos.

Segundo Lourenzani (2006), outro importante fator que contribui para a dificuldade na comercialização dos produtos da agricultura familiar é o baixo poder de barganha. Os lotes reduzidos de produção, as dificuldades em acessar economias de escala e as pequenas quantidades produzidas colocam os produtores familiares em uma posição de baixo poder de barganha frente aos seus compradores. Considerando como exemplo o setor de frutas, verduras e legumes, devido principalmente à alta inadimplência no segmento, os produtores preferem receber o preço estimado pelos permissionários ou atacadistas, pois têm neles a certeza de que irão receber por seus produtos, mesmo que não considerem um preço justo.

Visando diminuir os efeitos negativos das falhas de mercado, o Governo Federal tem instituído instrumentos de políticas públicas que proporcionam à agricultura familiar acesso ao crédito e aos mercados, proteção e melhoria da renda e incremento da produtividade. Dentre estes instrumentos podemos citar: o Programa Nacional de Fortalecimento da Agricultura Familiar (PRONAF), o Seguro da Agricultura Familiar (SEAF), Programa de Garantia de Preços da Agricultura Familiar (PGPAF), o Programa Nacional de Alimentação Escolar (PNAE) (BRASIL, 2013C).

Um dos instrumentos instituídos pelo governo federal com participação dos governos estaduais e municipais é o Programa de Aquisição de Alimentos (PAA). O PAA constitui-se como uma das ações do Programa Fome Zero ${ }^{2}$ que visa atender as populações em situação de insegurança alimentar e nutricional. O PAA é uma política pública que busca fortalecer a agricultura familiar e atender àqueles que não têm acesso aos alimentos em quantidade, qualidade e regularidade necessárias.

O PAA foi instituído pelo art. 19 da Lei $n^{\circ} 10.696$, de 2 de julho de 2003, sendo que uma das finalidades é " [...] incentivar a agricultura familiar, promovendo a sua inclusão econômica e social, com fomento à produção com sustentabilidade, ao processamento de alimentos e industrialização e à geração de renda" (BRASIL, 2012B).

Para participar do Programa, as famílias produtoras devem estar enquadradas no PRONAF, sendo identificadas como agricultores familiares ou acampados da Reforma Agrária, podendo ser aquicultores, pescadores artesanais, silvicultores, extrativistas, quilombolas e assentados. Esta identificação é comprovada por meio da Declaração de Aptidão ao PRONAF - DAP, que pode ser obtida junto a Instituições previamente autorizadas.

Segundo dados da Companhia Nacional de Abastecimento (CONAB), os recursos repassados pelo Ministério do Desenvolvimento Social e Combate à Fome (MDS) e pelo

2 "O Programa FOME ZERO é uma estratégia impulsionada pelo governo federal para assegurar o direito humano à alimentação adequada às pessoas com dificuldades de acesso aos alimentos. Tal estratégia se insere na promoção da segurança alimentar e nutricional, buscando a inclusão social e a conquista da cidadania da população mais vulnerável à fome." (PRESIDÊNCIA DA REPÚBLICA FEDERATIVA DO BRASIL, 2013). 
Ministério do Desenvolvimento Agrário (MDA) para aquisição de produtos, teve um aumento significativo ao longo dos anos. Em 2003, no início do Programa, os recursos aplicados foram R \$ 81,5 milhões, já em 2011 o montante aplicado foi de $\mathrm{R} \$ 586,5$ milhões, o que evidencia um aumento de 719,35\% (CONAB, 2013A).

Vários trabalhos acadêmicos acerca do PAA são citados na literatura. Müller (2007) ao analisar o PAA enquanto política pública, concluiu que o Programa traz em sua concepção a importância da agricultura familiar para o desenvolvimento da sociedade brasileira, pois busca o desenvolvimento equitativo de um setor excluído da economia e valoriza a atuação do agricultor familiar enquanto ator. Já Vieira (2008), buscou analisar o PAA enquanto canal de comercialização no município de Paracatu, Minas Gerais. Seu estudo concluiu que o Programa não influenciou o aumento de escala da produção, bem como não há uma preocupação por parte dos agricultores familiares daquele município com a regularidade da oferta e, apesar dos produtos terem sido classificados como de boa qualidade, inexistem instrumentos que possam atestá-los.

Deves (2009) analisou o PAA em São Pedro do Butiá, município do Rio Grande do Sul. Buscou verificar através deste Programa o fortalecimento da agricultura familiar a médio e longo prazo. Concluiu que, em sua maioria, os agricultores familiares não dependem do PAA e que apesar dos preços recebidos não atenderem suas expectativas, a garantia de compra dos produtos é fator determinante. Já para Andrade Júnior (2009), ao analisar o PAA no município de Mafra, em Santa Catarina, em algumas cadeias produtivas, o Programa atuou como regulador e estabilizador de preços no mercado local, favorecendo a melhoria da renda e a geração de trabalho/ emprego. Seu trabalho também demonstrou que o Programa fortaleceu as organizações, estimulando-as a participarem da economia local. Por fim, Raupp, Rinaldi e Rocha Júnior (2010) procuraram verificar a inserção do PAA nos municípios que constituem a região administrativa de Toledo, Paraná, e constataram problemas como: descompasso do fluxo de recursos financeiros, deficiências no processo de capacitação, assistência técnica e organização dos produtores e deficiências no processo de informação e divulgação do Programa.

Apesar dessas evidências, algumas questões persistem quando consideramos o nível não agregado como: o Programa tem sido efetivo no aumento da renda dos produtores familiares? Quais são as barreiras e os desafios encontrados pelo produtor referente ao sistema de comercialização?

Partindo do pressuposto que o PAA é uma política pública que busca fortalecer a agricultura familiar na medida em que diminui os efeitos negativos das falhas de mercado, este trabalho teve como objetivo analisar o Programa no município de Tupã. Para isso, foram analisadas as seguintes variáveis: a dinâmica de adesão; o aumento da renda; o PAA como canal de comercialização da agricultura familiar; e as dificuldades percebidas pelos produtores.

\section{Material e Método}

Para alcançar o objetivo proposto realizou-se primeiramente pesquisa bibliográfica, utilizando-se de livros, dissertações, informações disponibilizadas nos sites do Ministério do Desenvolvimento Agrário (MDA), do Ministério do Desenvolvimento Social e Combate à Fome (MDS), da Companhia Nacional de Abastecimento (CONAB), da Fundação Sistema Estadual de Análise de Dados (SEADE), do Instituto Brasileiro de Geografia e Estatística (IBGE) e da Coordenadoria de Assistência Técnica Integral (CATI). Tal pesquisa serviu de subsidio para as etapas posteriores.

Buscou-se então realizar uma pesquisa descritiva. Segundo Andrade (2006, p.124), na pesquisa descritiva "[...] os fatos são observados, registrados, analisados, classificados e interpretados, sem que o pesquisador interfira neles". Para Cervo e Bervian (2002, p.67) os estudos descritivos tratam "[...] do estudo e da descrição das características, propriedades ou relações existentes na comunidade, grupo ou realidade pesquisada".

A ferramenta utilizada para coleta de dados primários foi um questionário semi-estruturado aplicado aos produtores familiares participantes do PAA no município de Tupã. Um questionário piloto foi desenvolvido, aplicado e ajustado previamente à aplicação final. O questionário final buscou levantar as características destes produtores, considerando a renda anual da propriedade, a renda anual obtida através do PAA, à importância do PAA na comercialização de seus produtos, entre outros.

Considerando que a oferta de produtos agrícolas é sazonal, apesar de haver 70 produtores cadastrados no Programa, somente uma parcela deste grupo utiliza o PAA num mesmo período. Para viabilizar a análise, foi feito um recorte temporal e o questionário foi aplicado a todos os produtores familiares que realizaram entrega de produtos para o Programa de Aquisição de Alimentos no mês de dezembro de 2012, totalizando 25 produtores. Para uma melhor compreensão da sistemática do PAA, realizou-se também entrevista com a Secretaria da Agricultura do município, fiscalizadora do PAA, e com a Cooperativa Agrícola Mista da Alta Paulista (CAMAP), proponente do PAA que realiza a venda dos produtos para a CONAB.

\section{Resultados e Discussão}

\subsection{O Programa de Aquisição de Alimentos}

O PAA possui cinco modalidades de operação: (a) compra direta da agricultura familiar, (b) apoio a formação de estoques pela agricultura familiar, (c) incentivo à produção e ao consumo de leite (PAA - Leite), (d) compra institucional e, (e) compra com doação simultânea (BRASIL, 2013A).

No município de Tupã a modalidade do PAA operacionalizada é a compra com doação simultânea. Nesta modalidade 
os agricultores familiares enquadrados no PRONAF vendem seus produtos ao governo federal por meio das secretarias da agricultura municipais e estes são doados a famílias que estão em situação de insegurança alimentar e são assistidas por entidades assistenciais locais ou ainda a instituições atendidas por programas sociais tais como banco de alimentos, restaurantes populares e cozinhas comunitárias (BRASIL, 2013A). Neste caso, cada família produtora devidamente enquadrada no PRONAF pode ter acesso à no máximo $\mathrm{R} \$ 4,5$ mil por ano e os produtos a serem adquiridos deverão ser próprios para consumo humano, incluído os perecíveis, e característicos dos hábitos alimentares locais (BRASIL, 2013A). As famílias produtoras devem estar ligadas a uma cooperativa ou associação, pois estas irão intermediar a operação com a Conab, que efetuará o pagamento a esta cooperativa ou associação, que por sua vez repassará aos produtores familiares.

Em 2012, o valor de recursos distribuídos na modalidade compra com doação simultânea no país foi de R \$ 395 milhões, valor equivalente a $67,35 \%$ de $\mathrm{R} \$ 586,5$ milhões, total aplicado no PAA. Neste mesmo período, o valor distribuído por esta modalidade no estado de São Paulo foi de R\$ 57,7 milhões, o que o coloca na $1^{\circ}$ posição entre os estados na operacionalização do PAA por esta modalidade (CONAB, 2013A).

$\mathrm{O}$ número total de famílias de agricultores atendidas pelo PAA em 2012 no Brasil foi de 128.804, sendo que deste montante, 95.123 famílias de agricultores foram atendidas pela modalidade compra com doação simultânea (CONAB, 2013A). No estado de São Paulo foram 13.495 famílias agricultoras, sendo o estado com maior participação de agricultores familiares nesta modalidade, seguido por Minas Gerais (10.060 famílias agricultoras) e Santa Catarina (9.797 famílias agricultoras) (CONAB, 2013A).

Analisando o número de municípios participantes no PAA é possível verificar que a participação ainda é pouco expressiva. De um total de 5.564 municípios, apenas $21 \%$, ou seja, 1.180 participam do PAA no Brasil. Em São Paulo esta porcentagem é menor, apenas 20\%, 131 dos 645 municípios do estado participam do Programa (CONAB, 2013A).

\subsection{Caracterizações do município}

O município de Tupã está localizado na região centro -oeste do Estado de São Paulo denominada Alta Paulista. Segundo o Censo Demográfico realizado pelo IBGE em 2010, o município possui uma área de 628,513 km² e uma população de 63.475. Deste total, 60.929 encontra-se na área urbana e 2.546 na área rural, o que confere ao município um grau de urbanização de 95,99\% (SEADE, 2013A). A cidade tornou-se Estância Turística em 26 de maio de 2003, por meio da Lei nº 11.383 (Projeto de Lei no. 269/2000).

Destaca-se na economia do município o setor de serviços, seguida pela indústria e a agropecuária (Figura 1). É importante ressaltar que há várias agroindústrias, assim, a participação do agronegócio no PIB do município vai além da produção agropecuária.

Tupã é sede do Escritório de Desenvolvimento Rural da Coordenadoria de Assistência Técnica Integral (CATI). Este escritório abrange os municípios de Arco-Íris, Bastos, Herculândia, Iacri, Inúbia Paulista, Lucélia, Osvaldo Cruz, Parapuã, Pracinha, Queiroz, Rinópolis, Sagres, Salmourão e Tupã (CATI, 2013A). Segundo dados do Levantamento Censitário das Unidades de Produção Agropecuária do Estado de São Paulo (Projeto LUPA07/08) o município possui 1.114 Unidades de Produção Agropecuária (UPA) (SÃO PAULO, 2008). Destas, 986 UPAS são menores ou iguais a 4 módulos ficais, o que caracteriza o município com um grande número de pequenos produtores. Apesar de não haver dados oficiais, muitas destas UPAS são arredadas e outras são chácaras, utilizadas pelos proprietários como moradia (sendo que seus empregos são urbanos), ou para aluguel como lazer.

Atualmente, 146 produtores rurais possuem DAP no município (BRASIL, 2013B) e destes 70 participam do Programa de Aquisição de Alimentos em 2013 (CONAB, 2013B) (Figura 2).

Segundo dados do IBGE (2013), a produção agrope-

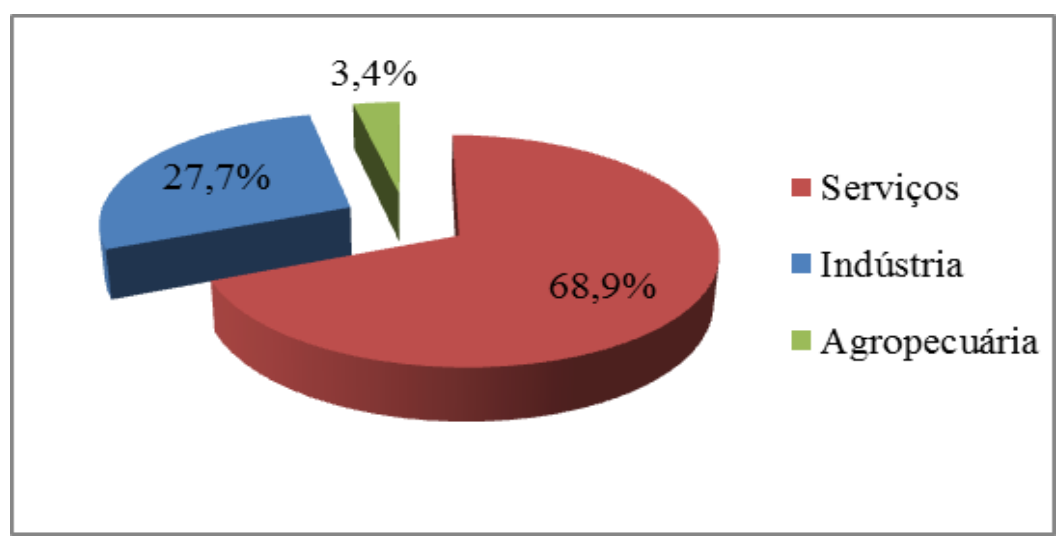

Figura 1 - Valor Adicionado total, por setores de atividade econômica, Produto Interno Bruto do município de Tupã em 2010 (em \%).

Fonte: Elaborada pela autora com base em SEADE, 2013B. 


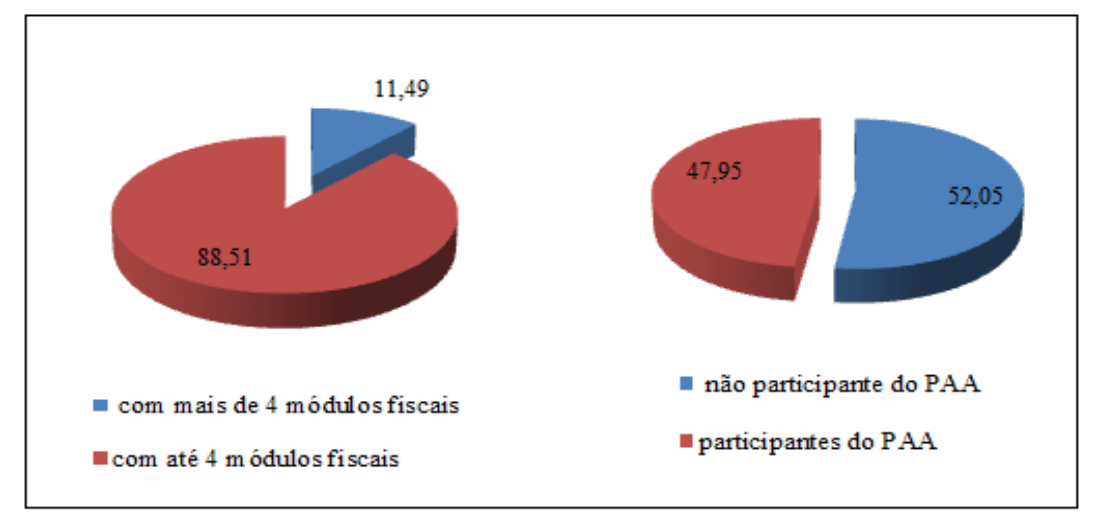

Figura 2 - Relação entre UPAS e números de participantes do PAA no município de Tupã (em \%). Fonte: Elaborada pela autora com base em SÃO PAULO (2008); BRASIL (2013B) e CONAB (2013B).

cuária no município de Tupã destaca-se pelo cultivo da cana-de-açúcar. Em 2011 o município produziu 1.068.600 toneladas de cana-de-açúcar, seguido pela produção de mandioca (50.000 t.) e pela produção de amendoim (14.875 t.). O município possuía, neste mesmo ano, um rebanho bovino com 54.786 cabeças e 1.920 .500 galinhas que produziram 40.691 dúzias de ovos.

O município conta com três cooperativas de produtores rurais de abrangência regional: a CAMAP (Cooperativa Agrícola Mista da Alta Paulista) que tem como foco a produção, secagem e armazenagem de amendoim, a COPLAP (Cooperativa dos Produtores de Leite da Alta Paulista) que atende os produtores de leite e a CERT (Cooperativa de eletrificação rural de Tupã) que fornece energia elétrica aos produtores associados. $\mathrm{O}$ município possui também dois sindicatos ligados ao setor rural: o Sindicato Rural patronal e o Sindicato dos Trabalhadores Rurais de Tupã. Conta ainda com duas associações formalizadas: a Associação dos Bananicultores de Tupã e a Associação dos Produtores de Leite de Tupã (CATI, 2013B).

\subsection{O PAA no município de Tupã/SP}

O PAA começou a ser operacionalizado no município de Tupã no ano de 2009. No início, participavam do Programa 35 agricultores familiares.

A primeira cooperativa proponente do Programa foi a Cooperativa Agrícola da Alta Paulista - CAMAP. Esta foi contatada pela Secretaria de Agricultura do município para realizar a intermediação entre os fornecedores e o PAA.

A fim de fortalecer a Associação dos Bananicultores de Tupã, em 2011 houve a troca da proponente, passando da CAMAP para a Associação dos Bananicultores, o que fez com que os agricultores familiares também se associassem à referida Associação. Por problemas de gerenciamento do Programa por parte da Associação dos Bananicultores, em 2012 a CAMAP retornou à função de proponente do PAA em Tupã. Este retorno foi uma solicitação da Secretaria da Agricultura e de alguns agricultores familiares associados à Associação por entenderem que a CAMAP possuía estrutura administrativa adequada para atender às demandas do Programa. Isto não onerou os agricultores, pois os mesmos eram cooperados da CAMAP e associados da Associação dos Bananicultores simultaneamente.

Atualmente, o PAA conta com a participação de 70 produtores familiares que estão cadastrados com 30 produtos e atendem 20 entidades assistenciais do município.

O Programa operacionalizado tem vigência de outubro/2012 a setembro/2013 e funciona como descrito a seguir:

Cada fornecedor é cadastrado com um único produto que, a cada entrega, tem seu peso convertido para o valor praticado de acordo com a tabela de preços disponibilizada pela Conab. As entregas ocorrem todas as terçasfeiras, das $07 \mathrm{~h} 30$ às $11 \mathrm{~h}$, no pátio de uma das entidades assistenciais que serve como central de distribuição;

Os produtos entregues são acondicionados em caixas plásticas e distribuídos proporcionalmente para cada entidade. A partir das $11 \mathrm{~h}$, cada entidade retira os produtos entregues e destinados a elas;

Após a entrega e distribuição dos produtos, é emitida uma nota fiscal de venda de cada fornecedor à CAMAP;

A CAMAP emite uma nota fiscal única de venda dos produtos para a CONAB. Juntamente com esta nota fiscal, é enviado mensalmente à CONAB o termo de recebimento e aceitabilidade de cada entidade, o relatório de entrega dos produtos divididos proporcionalmente por entidade e a declaração de vistoria do processo de recebimento dos produtos e entrega para as entidades;

A CONAB analisa então toda esta documentação e efetua o pagamento à CAMAP, que por sua vez efetua o pagamento a cada fornecedor (Figura 3).

O limite anual de entrega no momento da pesquisa era de $\mathrm{R} \$ 4.500,00$ para cada fornecedor inscrito no PAA. Sobre este valor é descontado $5 \%$ que fica para a proponente do Programa, e 2,3\% para o Fundo de Assistência ao Trabalhador Rural (FUNRURAL). Para que os fornecedores não atinjam o valor limite logo no início da vigência do Programa, a Secretaria da Agricul- 


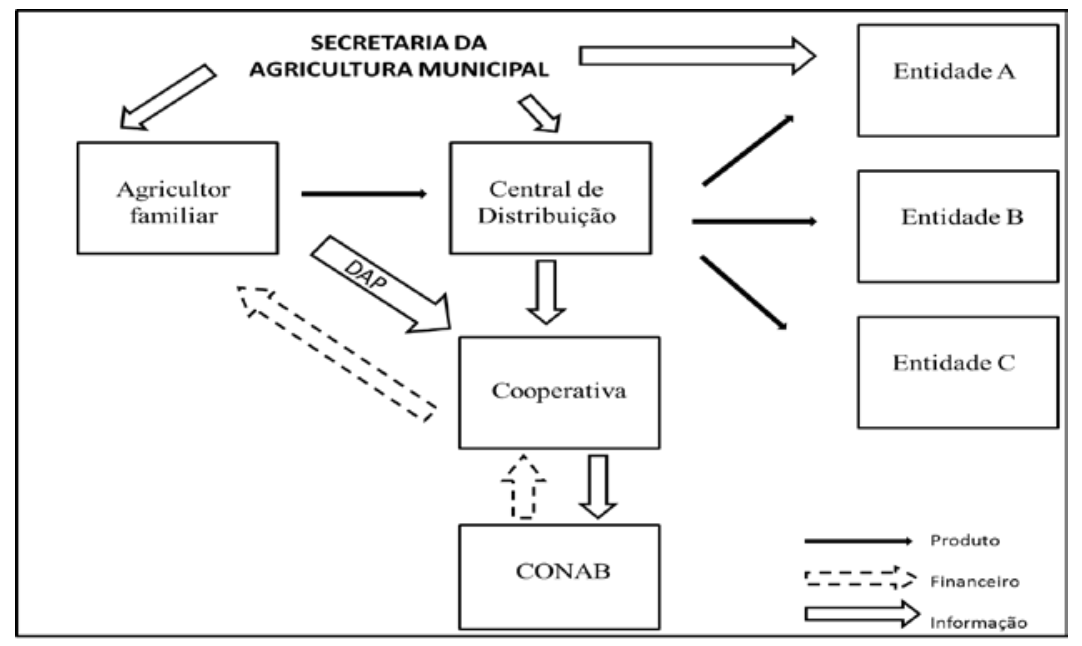

Figura 3 - Operacionalização do PAA no município de Tupã. Fonte: Elaborada pela autora.

tura realiza um controle semanal de entrega. Assim, o fornecedor terá a possibilidade de assegurar uma renda por um maior período de vigência do PAA. O controle de quantidades também é importante para assegurar o suprimento de alimentos às entidades beneficiadas ao longo do ano.

\subsection{Dinâmicas de adesão dos agricultores fa- miliares no PAA}

O início do PAA em Tupã não contou com a adesão de muitos agricultores familiares. Como em toda política pública em fase de implantação, houve muita desconfiança por parte dos agricultores familiares e foi necessário que a Secretaria da Agricultura fizesse o convite para que os mesmos participassem. Para aderir ao Programa, o agricultor familiar deveria ser cooperado e possuir DAP. Segundo dados do Projeto LUPA 2007/2008 (SÃO PAULO, 2008) havia no município, neste período, 571 produtores cooperados e mesmo assim, apenas 35 pro- dutores aderiram ao PAA (CONAB, 2013C). Isso ocorreu devido à desconfiança do Programa, considerando esta uma política pública recente.

Já em 2010 com o bom andamento do Programa e a superação da dificuldade de obtenção da DAP, houve um aumento de $40 \%$ na adesão e 50 agricultores familiares passaram a entregar seus produtos.

Em 2011 manteve-se o número de 50 participantes (CONAB, 2013B). Neste mesmo ano ocorreram as dificuldades de operacionalização do Programa com a Associação dos Bananicultores de Tupã. Houve atrasos no pagamento aos produtores por descontrole das entregas e por isso em 2012, ocorreu à troca da proponente e o retorno da operacionalização do Programa para a CAMAP. Mesmo assim, em 2012 houve novamente um aumento de $40 \%$ na adesão e 70 agricultores familiares participam atualmente do Programa (CONAB, 2013B) (Figura 4).

De acordo com a Secretaria da Agricultura, a adesão ao PAA tem aumentado, apesar dos problemas

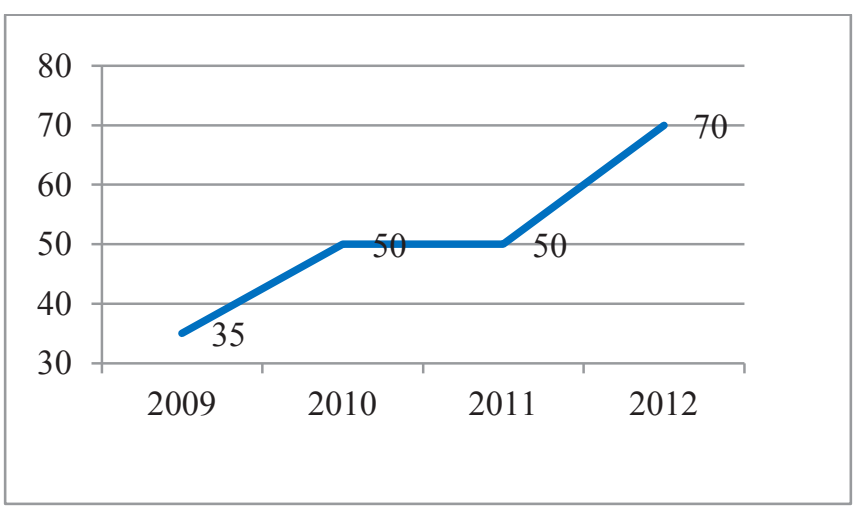

Figura 4 - Evolução da adesão de agricultores familiares ao PAA.

Fonte: Elaborada pela autora com base em CONAB, 2013B. 
ocorridos, porque os agricultores veem no Programa a possibilidade de entregarem o excedente da produção e ter uma renda extra e certa.

Para avaliar o impacto do PAA no aumento da renda, a pesquisa procurou verificar a renda anual total da propriedade e a percepção de aumento da renda que os agricultores familiares possuíam.

\subsection{Impactos do PAA no aumento da renda}

Houve dificuldade de coleta de dados sobre a renda, pois alguns produtores tiveram receio de responder às perguntas. Os resultados indicaram que dos 25 entrevistados, 36\% possui uma renda anual total de até $\mathrm{R} \$ 30$ mil, $12 \%$ de R\$31mil a R\$ 60 mil, 12\% de R\$ 61 mil a R\$
90 mil, e apenas $8 \%$ possuem renda anual total de mais de R\$ 90 mil, porém 32\% não souberam responder qual era sua renda anual total (Figura 5).

Com relação à percepção do aumento da renda, $84 \%$ do total dos entrevistados, afirmaram percepção do aumento após participação no PAA. Destes que responderam afirmadamente, 38\% acusaram um aumento de até $20 \%$ na renda, $24 \%$ acusaram um aumento entre $21 \%$ e $40 \%$ e $5 \%$ acusaram aumento entre $61 \%$ e $80 \%$. Novamente, $33 \%$ não souberam responder a porcentagem de aumento (Figura 6).

Pode-se então verificar que o PAA é fator de aumento da renda no município de Tupã na amostra e período analisados. Este aumento ocorre pelo simples fato do agricultor familiar poder escoar o excedente que ante-

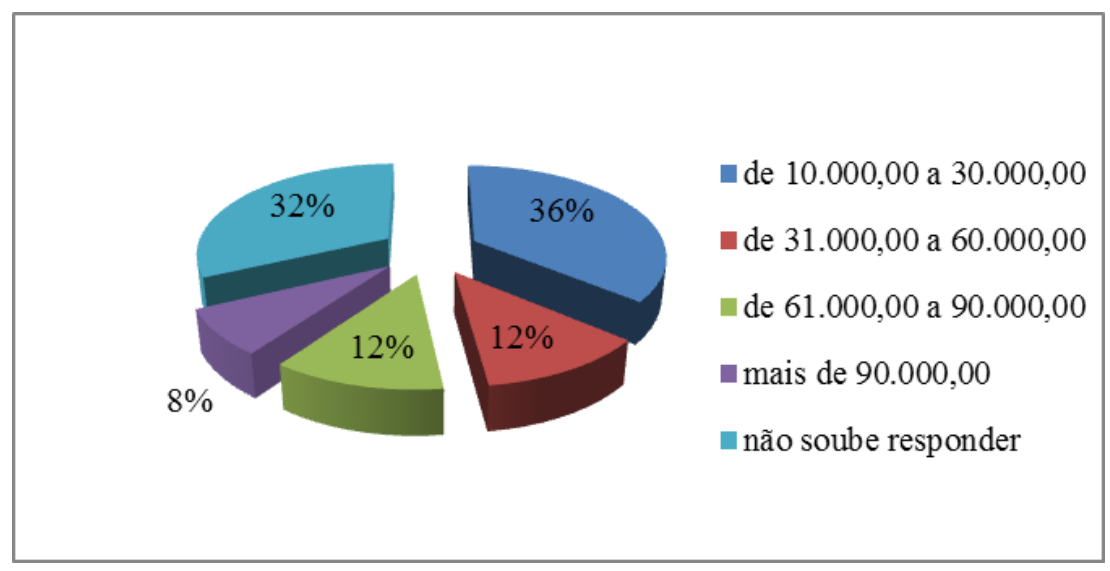

Figura 5 - Renda anual total dos agricultores familiares participantes do PAA.

Fonte: Elaborado pela autora.

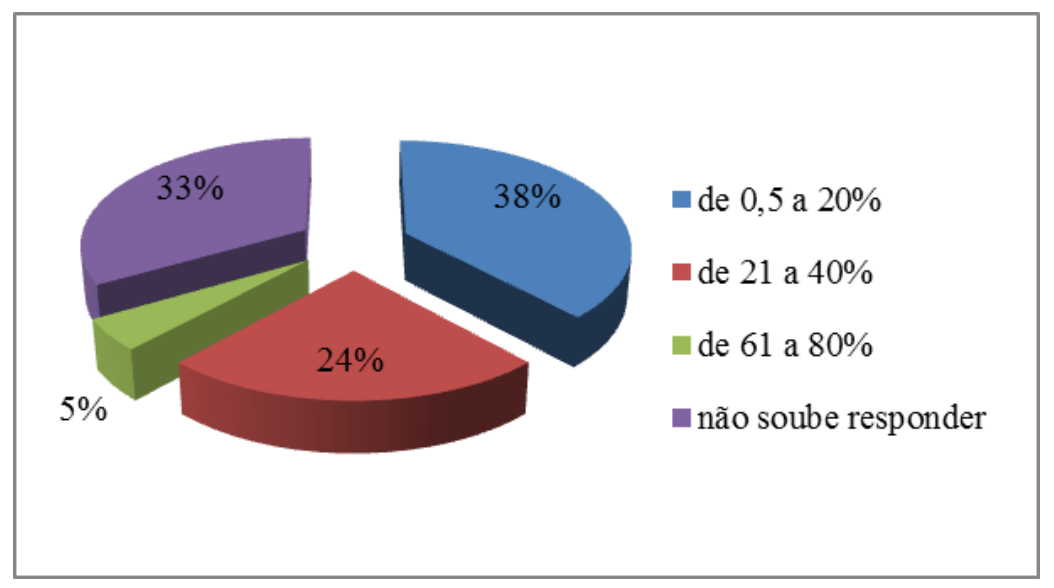

Figura 6 - Percepção do aumento da renda após iniciar participação no PAA.

Fonte: Elaborada pela autora 
riormente seria contabilizado como perda. Acredita-se que esse é um indicativo de fortalecimento da agricultura familiar uma vez que com um aumento da renda, o agricultor pode investir e diversificar sua produção, no sentido do aumento de eficiência e proteção contra os efeitos das falhas de mercado.

\subsection{PAA como canal de comercialização da agricultura familiar}

O PAA é uma política pública que visa proporcionar ao pequeno produtor o acesso ao mercado. Por isso, a pesquisa buscou verificar a relação entre os três principais produtos produzidos pelos produtores e a porcentagem de entrega do produto entregue no PAA.

Durante as entrevistas detectou-se que no município de Tupã, os principais canais de comercialização para os produtores familiares são os supermercados, as feiras livres e "atravessadores" ou "intermediadores", como identificados pelos produtores, que compram os produtos dos pequenos produtores e revendem para a CEAGESP (Companhia de Entrepostos e Armazéns Gerais de São Paulo). No caso da mandioca produzida pelo agricultor familiar as fecularias foram citadas como um importante canal de comercialização. No caso do milho, parte é destinada às granjas voltadas à produção de ovos, localizadas no município. Além destes, incluemse os programas governamentais de comercialização de produtos da agricultura familiar PNAE e PAA.

Considerando somente o PAA como canal de comercialização, dos 25 entrevistados apenas um produtor não participava do PAA com nenhum dos três principais produtos produzidos.

Como se pode observar na Figura 7, para o primeiro principal produto, 16 produtores comercializam até $20 \%$ de sua produção para o PAA, três produtores comercializam entre $21 \%$ e $40 \%$ da produção, um produtor comercializa entre $61 \%$ e $80 \%$ da produção e também um produtor comercializa entre $81 \%$ e $100 \%$ de sua produção.

Para o segundo principal produto, observa-se que apenas um produtor comercializa até $20 \%$ da produção no Programa e um produtor comercializa entre $81 \%$ e $100 \%$ da produção. Considerando o terceiro principal produto, apenas um comercializa entre 81 e 100\% do que produz por meio do PAA.

Esses dados indicam que os produtores que acessam o PAA o utilizam este canal de comercialização para com o objetivo de escoamento do excedente de produção e não como canal principal de comercialização. Outros canais são escolhidos dependendo de variáveis conjunturais como preço de mercado e demanda por produtos no momento da comercialização.

Dos agricultores familiares participantes do PAA entrevistados 12 participam também do PNAE. Alguns conheceram o PAA por causa da participação no PNAE. Não se observa concorrência do PAA com o PNAE, pois no PNAE as entregas são em quantidades determinadas e no PAA são entregues os excedentes da produção.

3.7 Dificuldades percebidas pelos produtores

A principal dificuldade percebida pelos agricultores familiares está relacionada aos atrasos nos pagamentos na vigência do Programa anterior (2011). Estes atrasos ocorreram devido à operacionalização deficiente do Programa. Segundo relatos da Secretaria da Agricultura, o Programa possui um controle complexo e rígido. Como o limite anual de entrega é baixo, isso faz com que o controle individual de cada produtor tenha que ser minuciosamente seguido para que os mesmo não ultrapassem suas cotas logo nas primeiras entregas. Foi justamente esta falta de controle que fez com que

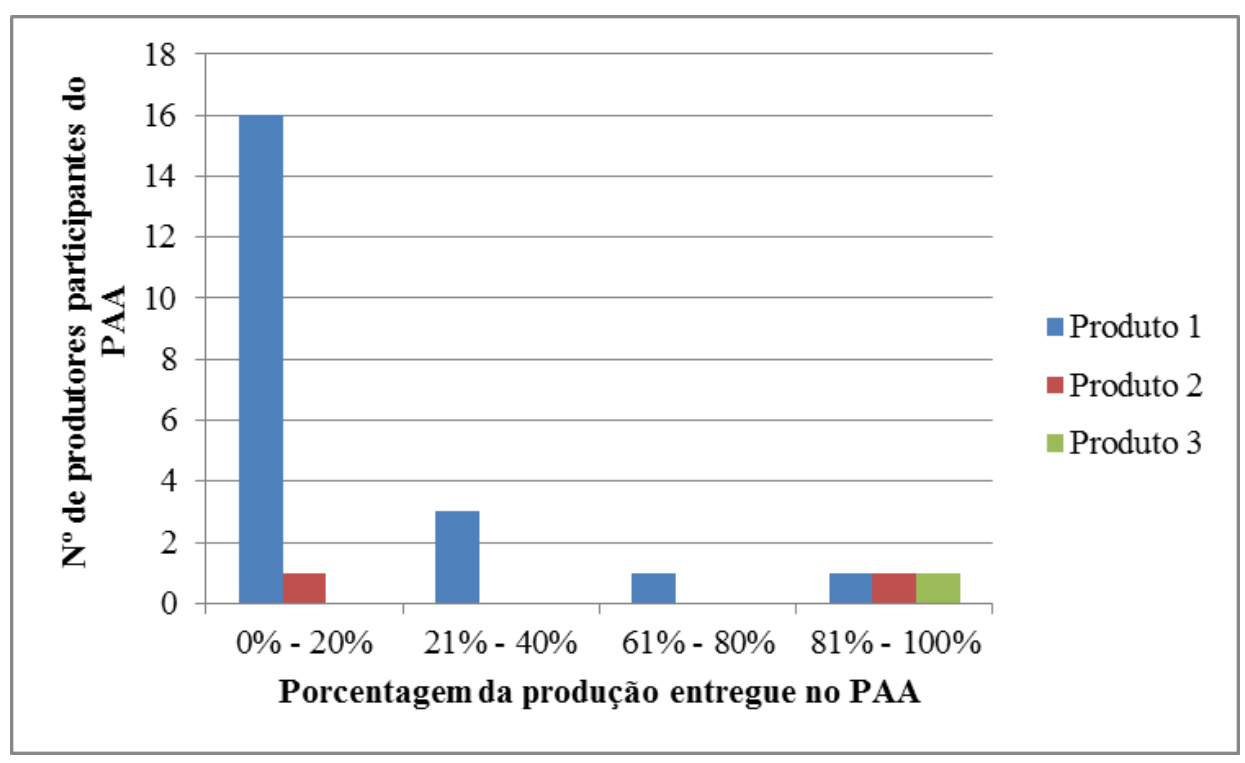

FIGURA 7 - Percentual dos 3 principais produtos produzidos e entregues no PAA.

Fonte: Elaborada pela autora. 
a organização proponente do Programa fosse alterada.

Uma segunda dificuldade apontada pelos produtores está relacionada aos preços praticados. Os produtores que entregam folhosas reclamaram pelo fato de as mesmas serem precificadas pelo Programa por meio do peso $(\mathrm{kg})$ e não por maço, como nos demais canais de comercialização. O preço do quilograma da folhosa é, em geral, aquém do preço praticado no mercado, onde é vendido por maço. Os produtores consideram que a tabela de preços utilizada pelo Programa geralmente está abaixo dos preços praticados no mercado, no entanto, ressalta-se que esta questão está relacionada à sazonalidade do produto e variação dos preços ao longo do ano.

Eles também apontaram o desejo de aumento do limite de entrega. Consideram o valor de $\mathrm{R} \$ 4.500,00$ baixo. Observou-se que os produtores têm excedentes superiores a esse valor. Tal fato sugere a dificuldade de acesso a outros canais de comercialização mais atrativos.

A participação nas ações coletivas também é um fato que dificulta a participação dos produtores no Programa. No início os produtores participavam de uma cooperativa motivada pela necessidade de atendimento às demandas do Programa e não pelo desejo de ser cooperado e assumir compromissos e benefícios de ser cooperado. No ano seguinte, os produtores se associaram e à já existente Associação dos Bananicultores de Tupã, com o objetivo de fortalecer a Associação. Porém, pelos problemas ocorridos na operacionalização do Programa pela Associação, alguns dos produtores associados e a Secretaria de Agricultura solicitaram a volta da cooperativa como proponente. Observa-se assim, que a cooperação não foi uma estratégia para fortalecimento dos produtores e sim, uma necessidade para acesso a uma política pública.

\section{Considerações Finais}

Os resultados indicaram que o PAA tem apresentado resultados positivos no município de Tupã. Foram verificados aumento da adesão de produtores ao longo do tempo. Os resultados ainda mostraram que houve aumento da renda e da possibilidade de acesso a mais um canal de comercialização.

Quanto à adesão ao PAA, observou-se que houve aumento no número de produtores desde a implantação do Programa. Entretanto, ainda há um baixo número de DAPs em relação ao número produtores familiares no município. Segundo a CATI de Tupã/SP, há dois motivos para esse valor. O primeiro é a falta de comprovação de renda agrícola uma vez que muitos não declaram ou declaram uma parcela reduzida das vendas por meio de notas fiscais. O segundo motivo é o recebimento de renda não agrícola.

Considerando o aumento da renda, verificou-se que o PAA se mostrou importante para a geração de renda. Cerca de $67 \%$ dos entrevistados percebeu aumento da renda em maior ou menor intensidade. Tal fato é relevante considerando que a renda pode proporcionar melhoria do bem-estar dos produtores, investimento na produção e diversificação das culturas, além de impacto no nível tecnológico adotado. Esses fatores contribuem para que a qualidade de produtos e processos dentro da propriedade rural possa ser melhorada.

Considerando o PAA como canal de comercialização, observou-se que o Programa funciona como uma alternativa para o escoamento do excedente de produção no município. A especificidade temporal dos produtos é elevada. Em sua grande maioria os produtos comercializados são do grupo de frutas, legumes e verduras (FLV) cuja perecibilidade é alta o que dificulta o processo de comercialização e reduz o poder de barganha dos produtores. Uma vez que o PAA é o canal de comercialização preferencial para escoamento do excedente, os produtores optam por um canal mais atrativo como primeira opção. Porém, o fato de os produtores sugerirem aumento das cotas sugere que os produtores estão utilizando o PAA como um canal de distribuição e não como opção de escoamento do excedente. Tal fato precisa ser investigado com mais profundidade.

Por outro lado, há barreiras a serem transpostas para o sucesso do PAA no município. Percebeu-se que as ações coletivas não são um processo endógeno, nem há elevado capital social envolvido. Os produtores estão cooperados pela necessidade de participarem do Programa e não há ações que fortaleçam a cooperação.

Além disso, falhas relacionadas ao controle e monitoramento das entregas foram percebidas. Assim, tornase necessário capacitar as pessoas que farão o controle do recebimento/pesagem dos produtos, bem como o lançamento dos controles para envio da documentação necessária à CONAB para posterior pagamento. Dessa forma, problemas como atraso nos pagamentos e troca de proponentes podem ser reduzidos e a eficácia do Programa pode ser aumentada.

Os resultados encontrados se aplicam ao município de Tupã, portanto os resultados não podem ser generalizados para outras regiões do país.

\section{Referências}

ANDRADE JÚNIOR, R.C.de. O Programa de Aquisição de Alimentos da Agricultura Familiar (PAA): o caso da Cooperativa Agropecuária Regional de Pequenos Produtores de Mafra (COOARPA). 116 f. Dissertação (Mestrado em Desenvolvimento Rural) - Programa de PósGraduação em Desenvolvimento Rural, Faculdade de Ciências Econômicas, Universidade Federal do Rio Grande do Sul, Porto Alegre, 2009.

ANDRADE, M M.de. Introdução à metodologia do trabalho científico: elaboração de trabalhos na 
graduação. São Paulo: Atlas, 2006.

BRASIL. Câmara Interministerial de Segurança Alimentar e Nutricional. Plano Nacional de Segurança Alimentar e Nutricional: 2012/2015. Brasília, DF: MDS; Consea, 2011. Disponível em: $<$ http://www.mds.gov.br/segurancaalimentar/ arquivos/LIVRO_PLANO_NACIONAL_CAISAN_ FINAL.pdf> Acesso em: 04 dez. 2012A.

BRASIL. Lei no 10.696, de 2 de julho de 2003. Dispõe sobre a repactuação e o alongamento de dívidas oriundas de operações de crédito rural, e dá outras providências. Disponível em: $<\underline{h t t p: / / w w w . ~}$ planalto.gov.br/ccivil 03/leis/2003/L10.696.htm >. Acesso em: 04 abr.2012B.

BRASIL. Lei no 11.326, de 24 de julho de 2006. Estabelece as diretrizes para a formulação da Política Nacional da Agricultura Familiar e Empreendimentos Familiares Rurais. Disponível em: <http://www.planalto.gov.br/ccivil_03/_ ato2004-2006/2006/lei/111326.htm >. Acesso em: 11 abr.2012C.

BRASIL. Ministério do Desenvolvimento Agrário. Secretaria da Agricultura Familiar. Programa de Aquisição de Alimentos - PAA: renda para quem produz e comida na mesa de quem precisam! Disponível em:<http://www.mds.gov.br/ segurancaalimentar/publicacoes\%20sisan/livros/ programa-de-aquisicao-de-alimentos-paa-rendapara-quem-produz-e-comida-na-mesa-de-quemprecisa/PROGRAMA \%20DE\%20AQUISICaO $\% 20$ DE\%20ALIMENTOS\%20PAA\%20-\%20Renda\%20 para $\% 20$ quem $\% 20$ produz $\% 20 \mathrm{e} \% 20$ comida $\% 20$ na\%20mesa\%20de\%20quem\%20precisa.pdf/view>. Acesso em: 04 dez.2013A.

BRASIL. Ministério do Desenvolvimento Agrário. Emissão de Extrato de DAP. Disponível em: $<$ http://smap14.mda.gov.br/dap/extrato/pf/ PesquisaMunicipio.aspx >. Acesso em: 10 fev.2013B

BRASIL. Ministério do Desenvolvimento Agrário. Plano Safra da Agricultura Familiar 2012/2013. Disponível em: <http://portal.mda.gov.br/ plano-safra/publicacoes/pageflip-view?pageflip_ $\mathrm{id}=10198443>$. Acesso em: 04 dez.2013C.

BUAINAIN, A.M.; PIRES, D. Reflexões sobre Reforma Agrária e Questão Social no Brasil - NEAD. Reforma Agrária, v. 1, p. 1-47, 2003. Disponível em: $<$ http://www.abda.com.br/texto/AntonioBuainain. pdf $>$. Acesso em 01 mar.2013.

CARVALHO, M.A.de. Políticas Públicas e
Competitividade da Agricultura. Revista de Economia Política, v. 21, n. 1 (81), jan./mar. 2001. Disponível em: <http://www.rep.org.br/pdf/81-7. pdf $>$. Acesso em: 15 mar.2013.

\section{CATI. COORDENADORIA DE ASSISTÊNCIA}

TÉCNICA INTEGRAL. Endereço dos escritórios regionais. Disponível em: $<$ http://www.cati.sp.gov. br/new/edr.php?cod_edr=39>. Acesso em: 11 fev.2013A.

\section{CATI. COORDENADORIA DE ASSISTÊNCIA} TÉCNICA INTEGRAL. Plano municipal de desenvolvimento rural sustentável 2010-2013: município de Tupã. Disponível em: <http://www. cati.sp.gov.br/new/cmdr.php?cod_mun=609>. Acesso em: 18 mar. 2013B.

CERVO, A.L.; BERVIAN, P.A. Metodologia científica. São Paulo: Prentice Hall, 2002.

\section{CONAB. COMPANHIA NACIONAL DE} ABASTECIMENTO. Programa de Aquisição de Alimentos - PAA: resultados das ações da Conab em 2012. Disponível em: <http:// www.conab.gov.br/OlalaCMS/uploads/ arquivos/13_02_07_08_31_25_sumario_ executivo_07_02_13.pdf >. Acesso em: 10 fev.2013A.

\section{CONAB. COMPANHIA NACIONAL DE}

ABASTECIMENTO. Transparência Pública do PAA - Programa de Aquisição de Alimentos. Disponível em: <http://consultaweb.conab. gov.br/consultas/consultatransparenciapaa. do? method=abrirConsulta $>$. Acesso em 10 fev.2013B.

\section{CONAB. COMPANHIA NACIONAL DE} ABASTECIMENTO. Resposta CONAB. [mensagem pessoal] Mensagem recebida por <mara@tupa. unesp.br> em 07 mar.2013C.

DEVES, O.D. Fortalecimento da agricultura familiar através do Programa de Aquisição de Alimentos - PAA: o caso do município de São Pedro do Butiá - RS. 157 f. Dissertação (Mestrado em Desenvolvimento Rural) - Programa de PósGraduação em Desenvolvimento Rural, Faculdade de Ciências Econômicas, Universidade Federal do Rio Grande do Sul, Porto Alegre, 2009.

\section{IBGE. INSTITUTO BRASILEIRO DE GEOGRAFIA}

E ESTATÍ́STICA. Censo Agropecuário 2006. Disponível em: <http://www.ibge.gov.br/home/ estatistica/economia/agropecuaria/censoagro/agri familiar_2006/familia_censoagro2006.pdf > . Acesso em: 04 abr.2012. 
IBGE. INSTITUTO BRASILEIRO DE GEOGRAFIA

E ESTATÍSTICA. IBGE Cidades@. Disponível em: <http://cidades.ibge.gov.br/xtras/perfil. php?lang=\&codmun=355500 $>$. Acesso em: 10 mar. 2013.

LOURENZANI, A.E.B.S. Condicionantes para inserção de pequenos produtores em canais de distribuição: uma análise das ações coletiva. 218 p. Tese (Doutorado em Engenharia da Produção) - Universidade Federal de São Carlos, São Carlos, 2006.

MÜLLER, A.L. A construção das políticas públicas para a agricultura familiar no Brasil: o caso do Programa de Aquisição de Alimentos. $128 \mathrm{f}$. Dissertação (Mestrado em Desenvolvimento Rural) - Programa de Pós-Graduação em Desenvolvimento Rural, Faculdade de Ciências Econômicas, Universidade Federal do Rio Grande do Sul, Porto Alegre, 2007.

\section{PRESIDÊNCIA DA REPÚBLICA FEDERATIVA DO}

BRASIL. Fome Zero. Disponível em: <http://www. fomezero.gov.br/>. Acesso em: 03 mar. 2013.

RAUPP, I.D.; RINALDI, R.N.; ROCHA, W.F.da; O Programa de Aquisição de Alimentos como canal de distribuição dos produtos da agricultura familiar: um estudo na região de Toledo - PR. In: CONGRESSO SOBER, 48., 2010, Campo Grande. Anais... Campo Grande: Sociedade Brasileira de Economia, Administração e Sociologia Rural, 2010. Disponível em: <http://www.sober.org.br/ palestra/15/235.pdf>. Acesso em: 18 mar. 2013.

SÃO PAULO (Estado). Secretaria de Agricultura e Abastecimento. Coordenadoria de Assistência Técnica Integral. Instituto de Economia Agrícola. Levantamento censitário de unidades de produção agrícola do Estado de São Paulo - LUPA 2007/2008. São Paulo: SAA/CATI/IEA, 2008. Disponível em: $<$ http://www.cati.sp.gov.br/projetolupa/>. Acesso em: 11 fev.2013.

SEADE - FUNDAÇÃO SISTEMA ESTADUAL DE ANÁLISE DE DADOS. Informações dos Municípios Paulistas - IMP. Disponível em: $<$ http://www.seade.gov.br/produtos/imp/index. 